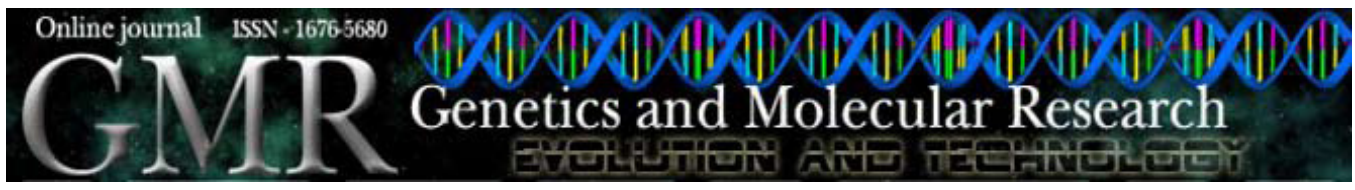

\title{
Prevalence of human papillomavirus (HPV) type 16 variants and rare HPV types in the central Amazon region
}

\author{
M.M. Castro ${ }^{1}$, I.P. Farias ${ }^{2}$, C.M. Borborema-Santos ${ }^{1}$, G. Correia ${ }^{3}$ and \\ S. Astolfi-Filho ${ }^{1}$ \\ ${ }^{1}$ Laboratório de Tecnologias de DNA, Universidade Federal do Amazonas, \\ Centro de Apoio Muldisciplinar, Manaus, AM, Brasil \\ ${ }^{2}$ Laboratório de Evolução e Genética Animal, Departamento de Biologia, \\ Universidade Federal do Amazonas, Manaus, AM, Brasil \\ ${ }^{3}$ Fundação Centro de Controle de Oncologia, Manaus, AM, Brasil \\ Corresponding author: S. Astolfi-Filho \\ E-mail: spartaco.biotec@gmail.com
}

Genet. Mol. Res. 10 (1): 186-196 (2011)

Received September 8, 2010

Accepted November 2, 2010

Published February 8, 2011

DOI 10.4238/vol10-1gmr992

\begin{abstract}
Infection by human papillomavirus (HPV) is one of the primary causes of mortality by cancer in northern Brazil. Sexually active women from Manaus, Amazonas, without cytological alterations and women with pre-malignant and malignant cytological alterations were examined for HPV virus, identified via PCR and sequencing. The target region for this study was part of the L1 capsid gene of HPV. Twentythree samples that were PCR-positive were sequenced. Analysis of 336 bp demonstrated a high incidence of high-risk HPV types in the population of Manaus, identified as HPVs 16, 33, 58, 66, 68. HPV type 16 was the most prevalent, presenting two variants similar to the AsianAmerican (AA) and East-Asian type (As) variants. A rare HPV type 13 related to "Heck's disease" was also detected. This preliminary provides important information about the HPV circulating in Amazonas State.
\end{abstract}

Key word: HPV; PCR; Amazon region; Cervical cancer 


\section{INTRODUCTION}

Based on research conducted during the last few years, the human papillomavirus (HPV) is a factor of great importance in the genesis of neoplasias in the female genital tract. Various studies point to HPV as an agent of malignant transformation of the cell, as one of the triggering factors of cervical cancer. The International Agency for Cancer Research (IARC) of the World Health Organization (WHO), concluded that, in view of the current evidence based on biological and epidemiological characteristics, certain papilloma viruses are carcinogenic in humans (Koshiol et al., 2008).

Wright and Herzog (2002) reported that cervical cancer continues to be a major public health problem, both in developed nations and in the developing world; approximately $99 \%$ of cervical carcinomas are positive for HPV DNA. They recommend the implementation of diagnostic tests for this virus in clinical practice.

The human papilloma viruses belong to the family Papillomaviridae; they are characterized by a double-stranded DNA with a genome size of about $8000 \mathrm{bp}$ and an icosahedral capsid approximately $55 \mathrm{~nm}$ in diameter (de Villiers et al., 2004). To date, at least 100 types of HPV have been identified, and this number continues to grow; 35 HPV types infect the female genital tract, and 30 are associated with cancer (de Villiers et al., 2004).

In Brazil, there were an estimated 18,680 cases of uterine cervical cancer in 2008, with 19 cases per 100,000 women (Instituto Nacional do Cancer - INCA, 2008; www.inca. gov.br/conteudo_view.asp?id=1793). It is estimated that the northern regions of Brazil have an incidence of 22/100,000 cases, the highest level of incidence in Brazil (INCA, 2008).

According to IARC (2007), cervical cancer is the second most common type of cancer among women in the world, with an estimated 471,000 new cases (and 233,000 deaths) in 2000 (Parkin et al., 2001). Almost $80 \%$ of the cases occur in developing countries, such as Brazil, where it is estimated that every year about 19,603 women are diagnosed with cervical cancer and 8286 die from the disease WHO/ICO Information Centre on HPV and Cervical Cancer (HPV Information Centre; http://www.who.int/hpvcentre/ publications/HPVReport2007.pdf) summary report on HPV and cervical cancer statistics in Brazil, 2007). Cervical cancer is the most common disease in Brazilian women, and infection by HPV is the main risk factor for development of this pathology. In Brazil, most studies of HPV were conducted in southeastern (Villa et al., 2000) or in central regions of the country (Cruz et al., 2004; Alencar et al., 2007; Cerqueira et al., 2008).

Although it is known that the northern region of Brazil has the highest level of incidence of cervical cancer, there is no published information concerning molecular characterization of the HPV virus circulating in the Amazon region. In northern Brazil, especially in the Amazon, there is a high incidence of cervical cancer, which unlike in other regions and countries is more prevalent than breast cancer. In Manaus, data from the Fundação Centro de Controle de Oncologia do Amazonas for 2002 showed that of the 1004 women diagnosed with cancer, 53\% had cervical cancer, which makes it the most frequent cancer in women of this region.

Our objective was to investigate the diversity and the prevalence of the different types of HPVs that occur in the Amazon. The target region for this molecular biology study was part of the L1 capsid gene of HPV, which is genetically conserved among all members of the papillomavirus family (de Villiers et al., 2004). 


\section{MATERIAL AND METHODS}

\section{Source of the biological material}

Samples were obtained from women seeking cytological services in Manaus, and were divided into two groups. One group comprised 61 women who, without clinical diagnosis, sought out the services of the Cytology Laboratory of the Pharmacy Course of the Departamento de Análises Clínicas e Toxicológicas - DACT - da Faculdade de Ciências da Saúde da Universidade Federal do Amazonas, in Manaus. The second group comprised 83 women who sought the gynecology services of the Fundação Centro de Controle de Oncologia do Amazonas - FCECON, with a diagnosis suggestive of infection with HPV: mild, moderate or severe dysplasia, in situ carcinoma, microinvasive cancer, weakly invasive carcinoma, or cervical adenocarcinoma.

The benefits and risks involved in participating in the groups were made clear to the patients before seeking their signature in a declaration of consent. The research was approved by the Institutional Ethics Committee in Human Research.

\section{Collection of material and extraction of DNA}

The samples were collected with Accellon-type cervical brushes and stored in 1.5$\mathrm{mL}$ Eppendorf tubes containing $400 \mu \mathrm{L}$ TE buffer solution $(50 \mathrm{mM}$ Tris- $\mathrm{HCl}, \mathrm{pH} 8.0$, and 1 mM EDTA) and maintained at $-20^{\circ} \mathrm{C}$. Two protocols were utilized for DNA extraction: the method described by Bauer and Manos (1993) and the method described by Sambrook et al. (1989). Two DNA extraction systems were used due to the fact that some samples contained a very high concentration of protein or blood that did not allow for efficient DNA extraction with the method described by Bauer and Manos (1993). Those samples that produced no polymerase chain reaction (PCR) product were re-extracted with a phenol-chloroform protocol (Sambrook et al., 1989).

Four blank extractions were carried out to check for contamination; no DNA contamination was observed. The quality of the DNA was assessed by amplifying a 268-bp fragment of B-globin as a positive control (Lefevre et al., 2003).

\section{PCR amplification and sequencing}

Contamination at the PCR step was checked by running a negative control (all PCR reagents but extracted DNA). To screen for the presence of HPV, we used PCR, but avoided nested PCR to minimize chances of false positives. A study by Nonogaki et al. (2004) demonstrated that the ability of the two tests to detect HPV is identical; therefore, we feel confident about our PCR results. The PCR amplifications were done with the primers MY11 (5'-GCMCAGGGWCATAAYAATGG-3') and MY09 (5'-CGTCCMAARGGAWACTGATC3'), which are among the most commonly used (Qu et al., 1997) for the amplification of approximately 450-bp fragments of the L1-conserved region of a wide spectrum of HPV genotypes (Bauer and Manos, 1993). PCRs were performed in a $50-\mu \mathrm{L}$ final volume containing $17.5 \mu \mathrm{L}$ Milli-Q water, $5.0 \mu \mathrm{L}$ 10X buffer ( $500 \mathrm{mM} \mathrm{KCl}, 100 \mathrm{mM}$ Tris-HCl, $\mathrm{pH} 8.5), 8.0 \mu \mathrm{L}$ $25 \mathrm{mM} \mathrm{MgCl}, 10 \mu \mathrm{L} 2.5 \mathrm{mM}$ dNTPs, $2.0 \mu \mathrm{L} 35$ pmol MY09, $2.0 \mu \mathrm{L} 35$ pmol MY11, 0.5 
$\mu \mathrm{L}$ Taq polymerase $(5 \mathrm{U} / \mu \mathrm{L})$ and $5.0 \mu \mathrm{L}$ genomic DNA $(\sim 30 \mathrm{ng})$. Amplifications were done in an Eppendorf-Mastercycler gradient thermocycler, as follows: denaturation at $95^{\circ} \mathrm{C}$ for $1 \mathrm{~min}$, annealing at $55^{\circ} \mathrm{C}$ for $1 \mathrm{~min}$, and extension at $72^{\circ} \mathrm{C}$ for $1 \mathrm{~min}$ repeated for $35 \mathrm{cycles}$, followed by a final extension of $5 \mathrm{~min}$ at $72^{\circ} \mathrm{C}$. To verify that the observed sequence variation was not due to the use of a non-proofreading Taq polymerase, whose rate of incorporating incorrect nucleotides is on the order of $10^{-4}$ (Tindall and Kunkel, 1988), we amplified and sequenced all samples at least twice.

A 5- $\mu \mathrm{L}$ sample of each PCR product was electrophoresed on $1 \%$ agarose gel and stained with ethidium bromide for visualization on a Pharmacia Biotech Image Master ${ }^{\mathbb{B}}$ VDS FTI-500. Amplified products were purified using "QIAquick ${ }^{\circledR}$ PCR Purification Kit QIAGEN", following manufacturer instructions. Samples were sequenced with the MY11 primer. Sequencing was performed in an automatic MegaBace 1000 using the DYEnamic ETterminator Kit, following manufacturer instructions. Sequences were edited and aligned in the BioEdit Version 5.0.6 program (Hall, 1999).

For the best visualization of relationships between HPV sequences obtained in our study and those available in GenBank, we performed a phylogenetic analysis using the MrBayes 3.1 software, which performs Bayesian inference of phylogenetic relationships (Ronquist and Huelsenbeck, 2003). Bayesian support values are calculated automatically during tree reconstruction. One million replicates were used and a $50 \%$ majority rule consensus tree was computed. The MEGA program (Kumar et al., 2004) was used to generate the genetic distance between HPV types (uncorrected p-distance).

\section{RESULTS}

One hundred and forty-four women took part in this study, of whom 61 were in the control group and 83 in the HPV group. Of the 61 samples from the control group, four patients possessed the 450-bp fragment of the viral capsid of HPV, whereas of the 83 samples from the HPV group, 32 patients possessed this fragment. Thirty-eight samples were PCR-positive for HPV DNA; however, 15 sequences were not of good quality and were discarded from the analysis. After the edition of the remaining 23 samples, 336-bp fragments of the partial sequences of HPV L1 were obtained (Table 1). Four samples were sequenced from the control group $(41 \mathrm{~F}, 42 \mathrm{~F}, 50 \mathrm{~F}, 62 \mathrm{~F})$ and 19 from the HPV group (1C, $2 \mathrm{C}, 4 \mathrm{C}, 6 \mathrm{C}, 7 \mathrm{C}, 9 \mathrm{C}, 10 \mathrm{C}, 14 \mathrm{C}, 17 \mathrm{C}, 19 \mathrm{C}, 21 \mathrm{C}, 29 \mathrm{C}, 32 \mathrm{C}, 37 \mathrm{C}, 42 \mathrm{C}, 66 \mathrm{C}, 79 \mathrm{C}, 84 \mathrm{C}$, 86C). All were deposited in GenBank under accession Nos. GQ396223-GQ396245. The 23 sequences were compared by BLAST with the sequences deposited in GenBank. Two hundred and one sites were variable (Table 2). HPV type 16 infection accounted for 56\% of the HPV infections found in women seeking cytological services in Manaus (within the HPV group, HPV type 16 accounted for $68 \%$ of the prevalence). The remaining $44 \%$ of the HPV-positive patients were infected with the following HPV types: in the control group: HPV type 33 (sample 42F), HPV type 66 (samples 41F and 50F); in the HPV group: HPV type 13 (sample 10C), HPV type 33 (samples 9C, 37C and 84C), HPV type 58 (samples 1C and 32C), and HPV type 68 (sample 14C).

Among the $336 \mathrm{bp}$ considered for the analysis, 130 characters were constants and 206 were variables, with 194 informative under parsimony. The mean base composition was $34 \%$ A, $18 \% \mathrm{C}, 17 \% \mathrm{G}$, and $30 \% \mathrm{~T}$. The estimated transition/transversion rate was 1.37 . The intra- 
HPV type genetic distance varied from $0 \%$ (in HPV type 13) to 5.2\% (in HPV type 68; Table 2). The inter-HPV type genetic distance was long, varying from $20.9 \%$ between HPV type 58 and HPV type 33, to $45.8 \%$ between HPV type 66 and HPV type 68.

\begin{tabular}{|c|c|c|c|}
\hline & GenBank accession No. & HPV type & Clinical diagnosis \\
\hline \multicolumn{4}{|c|}{ Group I } \\
\hline $41 \mathrm{~F}$ & GQ396243 & HPV66 & Without clinical diagnosis \\
\hline $42 \mathrm{~F}$ & GQ396239 & HPV33 & Without clinical diagnosis \\
\hline $50 \mathrm{~F}$ & GQ396244 & HPV66 & Without clinical diagnosis \\
\hline $62 \mathrm{~F}$ & GQ396234 & HPV16 & Without clinical diagnosis \\
\hline \multicolumn{4}{|c|}{ Group II } \\
\hline $1 \mathrm{C}$ & GQ396241 & HPV58 & LSIL \\
\hline $2 \mathrm{C}$ & GQ396224 & HPV16 & HSIL \\
\hline $4 \mathrm{C}$ & GQ396230 & HPV16 & HSIL \\
\hline $6 \mathrm{C}$ & GQ396225 & HPV16 & HSIL \\
\hline 7C & GQ396226 & HPV16 & HSIL \\
\hline $9 \mathrm{C}$ & GQ396237 & HPV33 & LSIL \\
\hline $10 \mathrm{C}$ & GQ396223 & HPV13 & Differential squamous carcinoma \\
\hline $14 \mathrm{C}$ & GQ396245 & HPV68 & LSIL \\
\hline $17 \mathrm{C}$ & GQ396227 & HPV16 & HSIL \\
\hline $19 \mathrm{C}$ & GQ396228 & HPV16 & Differential squamous carcinoma \\
\hline $21 \mathrm{C}$ & GQ396231 & HPV16 & HSIL \\
\hline $29 \mathrm{C}$ & GQ396232 & HPV16 & HSIL \\
\hline $32 \mathrm{C}$ & GQ396242 & HPV58 & HSIL \\
\hline $37 \mathrm{C}$ & GQ396238 & HPV33 & HSIL \\
\hline $42 \mathrm{C}$ & GQ396233 & HPV16 & No information \\
\hline $66 \mathrm{C}$ & GQ396235 & HPV16 & No information \\
\hline $79 \mathrm{C}$ & GQ396229 & HPV16 & Differential squamous carcinoma \\
\hline $84 \mathrm{C}$ & GQ396240 & HPV33 & HSIL \\
\hline $86 \mathrm{C}$ & GQ396236 & HPV16 & HSIL \\
\hline
\end{tabular}

LSIL = low-grade squamous intraepithelial lesion; HSIL = high-grade squamous intraepithelial lesion.

Preliminary characterization of the 36 HPV sequences obtained in this study were done by performing similarity searches with BLAST 2.0 (http://www.ncbi.nih.gov/blast). Our HPV sequences were most similar to HPV types deposited in GenBank: AF534061 East-Asian Variant, HPV16 AF472509 African Variant, HPV16 AF402678 Asian-American Variant, HPV33 U45895, HPV58 U45925, HPV66 U31794, and HPV68 (X67161, M73258, AJ831568). Surprisingly, one of the samples, 10C, was 99\% similar to HPV13 X62843, a type of HPV that is not related to cervical cancer. These reference sequences were used in phylogenetic analyses together with the 23 sequences that we obtained in this sample. The phylogenetic tree obtained through Bayesian analysis was well supported by high Bayesian posterior support values (Figure 1). The analysis revealed two HPV type 16 clusters, one composed of samples $02 \mathrm{C}, 06 \mathrm{C}, 07 \mathrm{C}, 17 \mathrm{C}, 19 \mathrm{C}$, and $79 \mathrm{C}$ and another of samples $04 \mathrm{C}$, $21 \mathrm{C}, 29 \mathrm{C}, 62 \mathrm{~F}, 66 \mathrm{C}, 42 \mathrm{C}$, and $86 \mathrm{C}$. These clusters had an intra-cluster genetic distance that ranged from 0 to $1.0 \%$ (uncorrected p-distance) and an inter-cluster genetic distance that ranged from 2.8 to $3.2 \%$. The two clusters were unambiguously differentiated at six nucleotide sites (Table 2; sites 25, 107, 158, 169, 274, and 298). These two clusters formed a monophyletic group strongly supported by a Bayesian posterior support value of 1.0.

The clades formed by samples $09 \mathrm{C}, 84 \mathrm{C}, 37 \mathrm{C}, 42 \mathrm{~F}$ and samples $01 \mathrm{C}$ and $32 \mathrm{C}$, which grouped with HPV types 33 and 58, respectively, showed high Bayesian support values. The group corresponding to samples $41 \mathrm{~F}$ and $50 \mathrm{~F}$ was grouped with HPV type 66, with a Bayesian support value of 1.0 . 
Table 2. Two hundred and one variable sites in the $336 \mathrm{bp}$ of the partial sequences of HPV L1 that were sequenced.

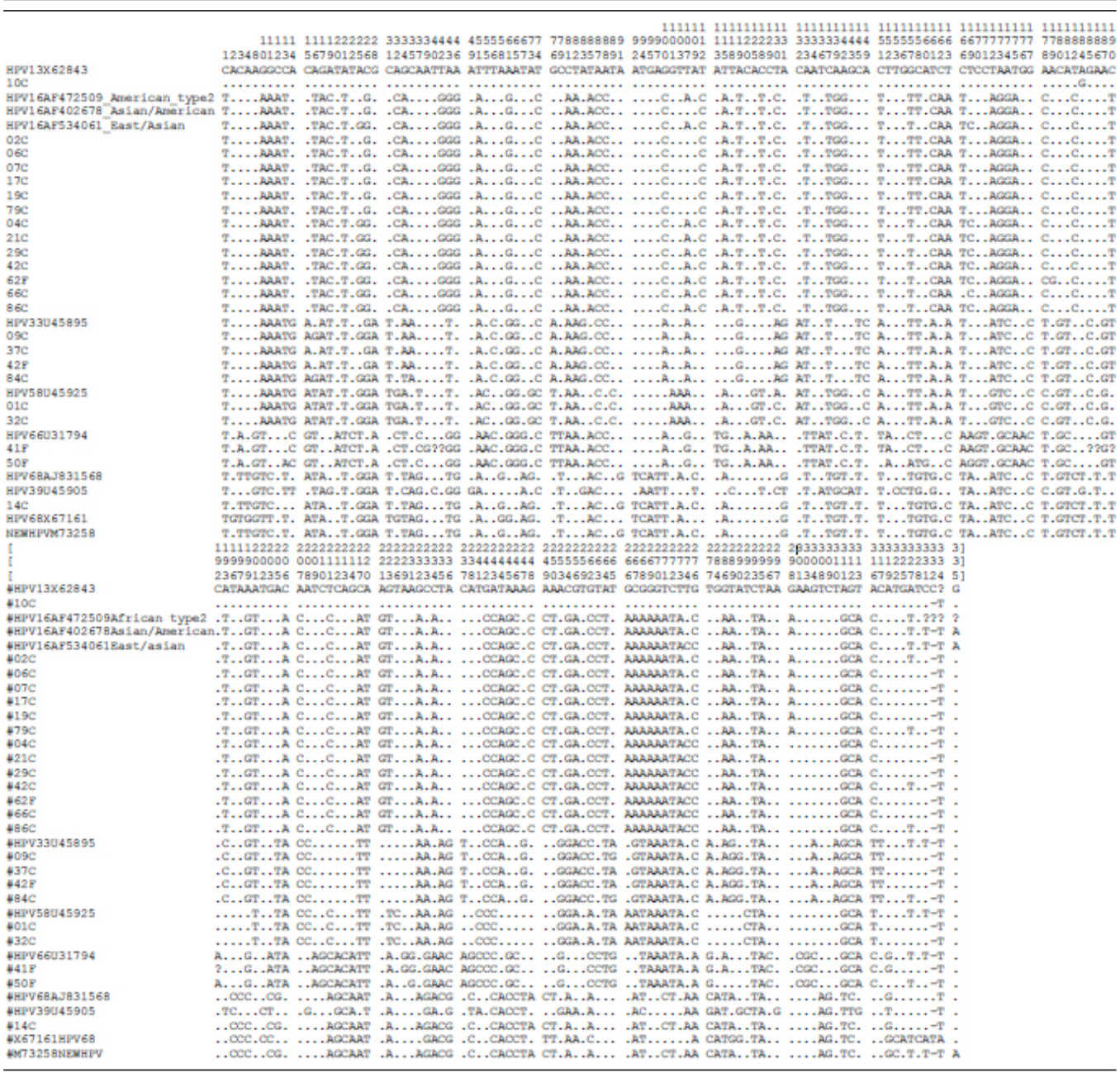

GenBank sequences assigned to known groups used in the study were included. Identity with the first sequence is denoted by a dot.

Sample 14C appeared most similar to the HPV integrated into a chromosome of carcinoma cell line ME180 (Reuter et al., 1991) and HPV68 (unpublished GenBank AJ831568), with a genetic distance between them of 0.9 and $0.5 \%$, respectively. The genetic distance between GenBank \#X67161, the HPV type 68 characterized by Longuet et al. (1996), and the clade formed by $14 \mathrm{C}+\mathrm{ME} 180+\mathrm{AJ} 83156$ was $11.2,10.1$, and $10.7 \%$, respectively (results not shown). On the other hand, the genetic distance between the HPV type 68 clade in relation to the other HPV types was large, varying from 25.3 (with HPV39) to $46.0 \%$ (with HPV66; Table 3). As Reuter et al. (1991) and Longuet et al. (1996) noted that the HPV from the lineage of cells ME180 and HPV68 (X67161) is closely related to HPV type 39, we also included the GenBank 
sequence of HPV type 39 (U45905; Stewart et al., 1996) in our analysis. The genetic distance between HPV type 39 and the clade formed by the HPV type 68 sequences was $25.3 \%$.

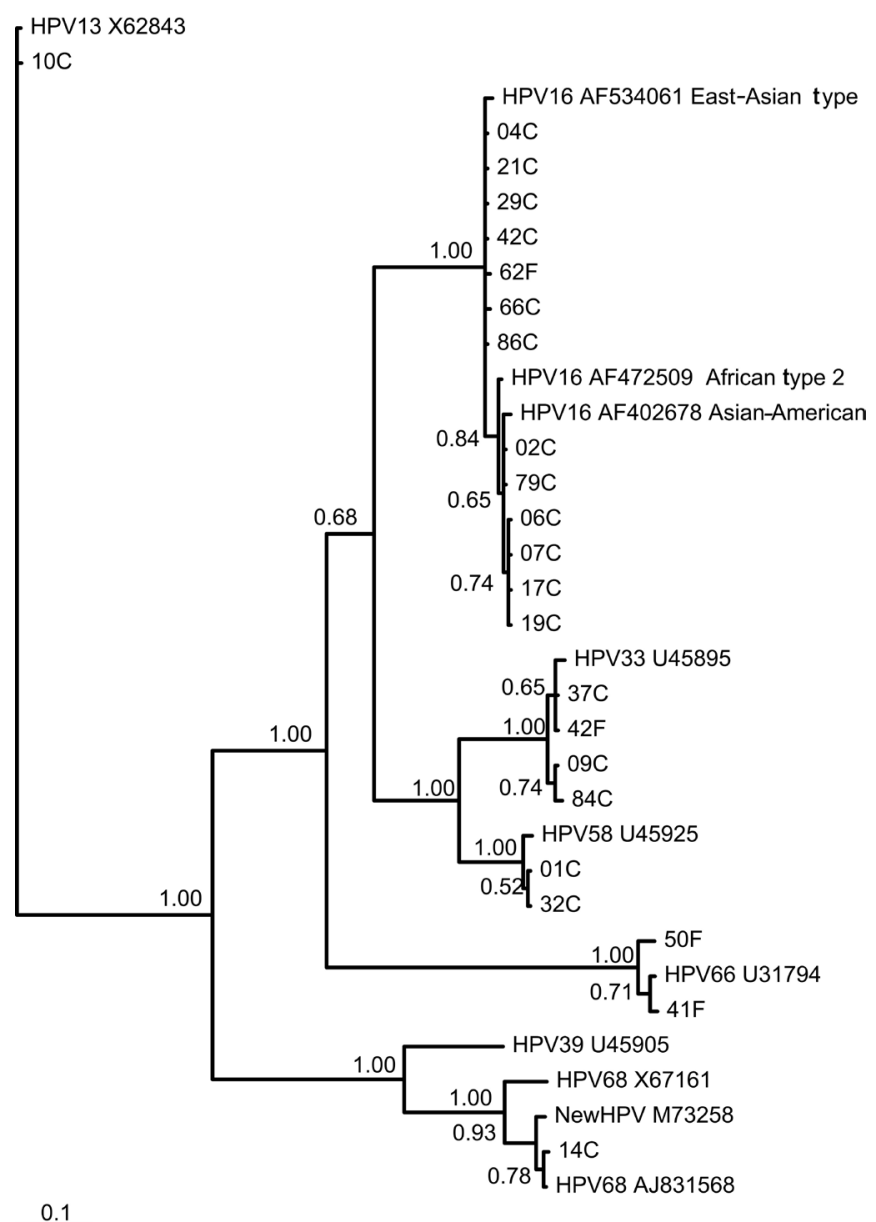

Figure 1. Unrooted Bayesian inference tree on HPV L1 gene data obtained using the HKY $85-\Gamma$ model of molecular evolution. Numbers above branches are Bayesian support values.

Table 3. Pairwise genetic distances (uncorrected p-distance) among HPV types.

\begin{tabular}{lccccccc}
\hline Among types & HPV13 & HPV16 & HPV33 & HPV39 & HPV58 & HPV66 & HPV68 \\
\hline HPV13 & - & & & & & & \\
HPV16 & 0.328 & - & - & & & & \\
HPV33 & 0.363 & 0.293 & 0.404 & - & & & \\
HPV39* & 0.388 & 0.399 & 0.208 & 0.406 & - & - & - \\
HPV58 & 0.360 & 0.267 & 0.373 & 0.454 & 0.378 & 0.460 & - \\
HPV66 & 0.409 & 0.367 & 0.421 & 0.253 & 0.423 & \\
HPV68 & 0.406 & 0.394 &
\end{tabular}

*Represented by a single sequence from GenBank (No. U45905). HPV68 type is composed by sample 14C, ME180, X67161, and HPV68 (unpublished GenBank No. U31794). 


\section{DISCUSSION}

\section{Prevalence of the types of HPV}

The almost 100 types of HPV that were described have been classified according to their biological properties into high-risk and low-risk HPV; the high-risk HPV are related to pre- and malignant lesions and the low-risk HPVs to benign lesions (de Villiers et al., 2004). We found a high incidence of high-risk HPV types in the population of Manaus, including HPV types $16,33,58,66$, and 68 , followed by the low-risk HPV types 6,11 , and 13 . HPV type 16 was the most prevalent (52.2\%), followed by HPV types $6(4 \%), 11(4 \%), 13(4 \%), 33(16 \%)$, $58(8 \%), 66(8 \%)$, and $68(4 \%)$. HPV type 16 is generally considered to be the most aggressive type, with significant oncogenic potential (Brady et al., 1999; Muñoz, 2000; Chaturvedi et al., 2004; Xi et al., 2002, 2006). The prevalence of HPV type 16 is highly related to some high-grade squamous intraepithelial lesion and differential squamous carcinomas (Table 1).

Our preliminary findings showing high prevalence of HPV type 16 are concordant with other studies that show it to be the most common HPV and to be associated with over $50 \%$ of cases of cervical cancers (Muñoz, 2000; Sichero and Villa, 2006). This was also found in southeastern (Villa et al., 2000) and central Brazil (Cruz et al., 2004; Alencar et al., 2007). Variants of HPV type 16 are typically classified into European, African, Asian-American, and North-American, or Amerindian (Yamada et al., 1997). The two HPV type 16 clusters observed in our study correspond to the Asian-American and East-Asian type variants. According to Yamada et al. (1997), the variant forms of HPV type 16 present a characteristic geographic distribution pattern, the Asian-American having greater frequency in Central America and South America. In the DNA region that we sequenced, the Asian-American variant differs by one nucleotide from the African type. Therefore, we cannot conclusively reject an African contribution to the observed HPV 16 types occurring in the Amazon.

Based on the comparison of the nucleotide sequences of the samples analyzed in our study together with sequence data obtained from GenBank, sample $14 \mathrm{C}$ had the greatest similarity to the viral strain isolated from the human cervix-derived epithelial cell line (ME180) (American Type Culture Collection, GenBank accession No. M73258) and HPV type 68 unpublished GenBank accession No. AJ831568 from Neophytou et al. (2004). Reuter et al. (1991) referred to HPV DNA in cervical carcinoma cells of the ME180 lineage as a new HPV and they suggested that it is very closely related to HPV type 39. Later, Longuet et al. (1996) suggested that the subgenomic ME180-HPV DNA fragment corresponds to an HPV68 subtype. The sample identified in our study (14C) came from an FCECON patient and had a cytological result described as "suggestive of HPV"; it differed from HPV 68 by $10.3 \%$. The taxonomic status of HPV types, subtypes, and variants is based on the traditional criteria that the sequence of their L1 genes should be at least 10\%, 2-10\%, and maximally $2 \%$ dissimilar from one another, respectively (de Villiers et al., 2004). Therefore, the sequences 14C, M73258, and AJ831568 should be considered sub-types of the HPV68, characterized by Longuet et al. (1996). HPV type 68 is related to high-risk type cervical carcinoma (Muñoz et al., 2003).

Another finding deserving attention was sample 10C, which to our surprise was very similar to HPV type 13. According to Pfister et al. (1983), HPV type 13 is found in the oral mucus, where it causes the so-called focal epithelial hyperplasia or "Heck's disease", first described in American Indians. Cases of this disease are considered to be relatively rare (Santil- 
lán, 2003). Ethnic differences in the prevalence of specific HPV types have not been previously reported, except for a predominance of Heck's disease or focal epithelial hyperplasia produced by HPV types 13 and 32 among American Indians (Archard et al., 1965) and North-American Eskimos (Jarvis and Gorlin, 1972). These types of HPV are associated with low-risk benign mucosal lesions (de Villiers et al., 2004). Sample 10C came from FCECON, the histological report referring to an "epidermoidal carcinoma moderately differentiated and ulcerated". The complete genome of this sample was sequenced by Santos-Borborema (2006) and is available in GenBank under accession No. DQ344807. Human papillomavirus is known as an etiological agent for cervical cancer; only recently has it been related to oro-pharyngeal cancers. However, little is known about the interrelationship between oral and cervical HPV infections. In a recent study, Fakhry et al. (2006), analyzing 221 women with paired specimens for oral and cervical sites of HPV infection and HIV serostatus, found that oral HPV infection was less common than cervical infection. Sixty-nine oral HPV infections were detected, including $57 \%$ low-risk infections and $43 \%$ high-risk infections. Twenty-six of the 37 HPV types were detected in the oral cavity. In that study, HPV types 45 and 83 were the most prevalent highrisk oral infections. High-risk types 51, 52, 53, 67, 68, and 73 and low-risk types 6, 40, 54, 57, and 64 were not detected in the oral cavity. Because of some limitation in the assay, the authors explained that HPV types associated with non-malignant oral lesions, such as 7, 13, 32, and $(16,36)$ would not be detected by their methods. Twenty-six of the 35 HPV types found to infect the cervix were also found within the oral cavity, and the type distribution for oral HPV infections appeared distinct from that for cervical infections. These authors concluded that the oral cavity can be a reservoir of HPV infection, with a sufficiently high prevalence to affect the dynamics of HPV transmission in populations.

In spite of being an isolated case in the Manaus sample, the presence of an oralspecific HPV type such as HPV type 13 in the genital region and other cases reported in the literature may indicate that HPV viruses are not as tissue specific as has been conventionally assumed and, therefore, HPV strain tropism should be studied further.

This was a preliminary study of the prevalence of HPV types present in the Amazonas State. Future studies should address rare HPV variants and the HPV type 16 variants circulating in Amazonian populations.

\section{ACKNOWLEDGMENTS}

Research supported by CNPq and the Universidade Federal do Amazonas. The authors are grateful to Zeliene Araújo de Souza, Ejandre L. Santiago and Joede de Oliveira from Fundação de Medicina Tropical do Amazonas for sample collection and collaborations. Permission to collect samples was granted by the Ethics Committee of the Fundação de Medicina Tropical do Amazonas (FMTAM). This study formed a portion of M.M. Castros' M.Sc. thesis requirements in the joint UFAM/UFSCar Genetics and Evolution Graduate Program.

\section{REFERENCES}

Alencar TR, Cerqueira DM, da Cruz MR, Wyant PS, et al. (2007). New HPV-16 European and non-European variants in Central Brazil. Virus Genes 35: 1-4.

Archard HO, Heck JW and Stanley HR (1965). Focal epithelial hyperplasia: an unusual oral mucosal lesion found in Indian children. Oral Surg. Oral Med. Oral Pathol. 20: 201-212. 
Bauer HM and Manos MM (1993). PCR Detection of Genital Human Papillomavirus. In: Diagnostic Molecular Microbiology, Principles and Application (Persing D, Smith T and Tenover F, eds.). American Society of Microbiology, Washington, 407-413.

Brady CS, Duggan-Keen MF, Davidson JA, Varley JM, et al. (1999). Human papillomavirus type 16 E6 variants in cervical carcinoma: relationship to host genetic factors and clinical parameters. J. Gen. Virol. 80 (Pt 12): 3233-3240.

Cerqueira DM, Raiol T, Veras NM, von Gal MN, et al. (2008). New variants of human papillomavirus type 18 identified in central Brazil. Virus Genes 37: 282-287.

Chaturvedi AK, Brinkman JA, Gaffga AM, Dumestre J, et al. (2004). Distribution of human papillomavirus type 16 variants in human immunodeficiency virus type 1-positive and -negative women. J. Gen. Virol. 85: 1237-1241.

Cruz MR, Cerqueira DM, Cruz WB, Camara GN, et al. (2004). Prevalence of human papillomavirus type 16 variants in the Federal District, Central Brazil. Mem. Inst. Oswaldo Cruz 99: 281-282.

de Villiers EM, Fauquet C, Broker TR, Bernard HU, et al. (2004). Classification of papillomaviruses. Virology 324: 17-27.

Fakhry C, D'souza G, Sugar E, Weber K, et al. (2006). Relationship between prevalent oral and cervical human papillomavirus infections in human immunodeficiency virus-positive and -negative women. J. Clin. Microbiol. 44: 4479-4485.

Hall T (1999). BioEdit: a user-friendly biological sequence alignment editor and analysis program for Windows 95/98/ NT. Nucleic Acids Symp. Ser. 41: 95-98.

IARC (2007). Monographs on the Evaluation of Carcinogenic Risks to Humans. Vol. 64. Human Papillomaviruses. International Agency for Research on Cancer, Lyon.

Jarvis A and Gorlin RJ (1972). Focal epithelial hyperplasia in an Eskimo population. Oral Surg. Oral Med. Oral Pathol. 33: $227-228$

Koshiol J, Lindsay L, Pimenta JM, Poole C, et al. (2008). Persistent human papillomavirus infection and cervical neoplasia: a systematic review and meta-analysis. Am. J. Epidemiol. 168: 123-137.

Kumar S, Tamura K and Nei M (2004). MEGA3: Integrated software for Molecular Evolutionary Genetics Analysis and sequence alignment. Brief. Bioinform. 5: 150-163.

Lefevre J, Hankins C, Pourreaux K, Voyer H, et al. (2003). Real-time PCR assays using internal controls for quantitation of HPV-16 and beta-globin DNA in cervicovaginal lavages. J. Virol. Methods 114: 135-144.

Longuet M, Beaudenon S and Orth G (1996). Two novel genital human papillomavirus (HPV) types, HPV68 and HPV70, related to the potentially oncogenic HPV39. J. Clin. Microbiol. 34: 738-744.

Muñoz N (2000). Human papillomavirus and cancer: the epidemiological evidence. J. Clin. Virol. 19: 1-5.

Muñoz N, Bosch FX, de Sanjosé S, Herrero R, et al. (2003). Epidemiologic classification of human papillomavirus types associated with cervical cancer. N. Engl. J. Med. 348: 518-527.

Neophytou PI, Tsitsanou KE, Philippidou D, Lerios S, et al. (2004). Identification of novel HPV subtypes and variants in Cyprus. Unpublished GenBank Accession Number AJ831568.

Nonogaki S, Wakamatsu A, Longatto FA, Pereira SM, et al. (2004). Hybrid capture II and polymerase chain reaction for identifying HPV infections in samples collected in a new collection medium: a comparison. Acta Cytol. 48: 514-520.

Parkin DM, Bray FI and Devesa SS (2001). Cancer burden in the year 2000. The global picture. Eur. J. Cancer 37 (Suppl 8): S4-S66.

Pfister H, Hettich I, Runne U, Gissmann L, et al. (1983). Characterization of human papillomavirus type 13 from focal epithelial hyperplasia Heck lesions. J. Virol. 47: 363-366.

Qu W, Jiang G, Cruz Y, Chang CJ, et al. (1997). PCR detection of human papillomavirus: comparison between MY09/ MY11 and GP5+/GP6+ primer systems. J. Clin. Microbiol. 35: 1304-1310.

Reuter S, Delius H, Kahn T, Hofmann B, et al. (1991). Characterization of a novel human papillomavirus DNA in the cervical carcinoma cell line ME180. J. Virol. 65: 5564-5568.

Ronquist F and Huelsenbeck JP (2003). MrBayes 3: Bayesian phylogenetic inference under mixed models. Bioinformatics 19: 1572-1574.

Sambrook J, Fritsch EF and Maniatis T (1989). Molecular Cloning: A Laboratory Manual. 2nd edn. Cold Springs Harbor Laboratory Press, Cold Springs Harbor, New York.

Santillán EM (2003). Hiperplasia epitelial focal (enfermidade de Heck). Reporte de un caso. Rev. Mex. Pediatr. 70: 132-134.

Santos-Borborema CM (2006). Sequenciamento e Análise do Genoma do HPV tipo 13 isolado na Amazônia. Doctoral thesis, Universidade Federal do Amazonas, Manaus.

Sichero L and Villa LL (2006). Epidemiological and functional implications of molecular variants of human papillomavirus. Braz. J. Med. Biol. Res. 39: 707-717.

Stewart AC, Eriksson AM, Manos MM, Munoz N, et al. (1996). Intratype variation in 12 human papillomavirus types: a worldwide perspective. J. Virol. 70: 3127-3136.

Tindall KR and Kunkel TA (1988). Fidelity of DNA synthesis by the Thermus aquaticus DNA polymerase. Biochemistry 27: 6008-6013. 
Villa LL, Sichero L, Rahal P, Caballero O, et al. (2000). Molecular variants of human papillomavirus types 16 and 18 preferentially associated with cervical neoplasia. J. Gen. Virol. 81: 2959-2968.

Wright JD and Herzog TJ (2002). Human papillomavirus: emerging trends in detection and management. Curr. Womens Health Rep. 2: 259-265.

Xi LF, Carter JJ, Galloway DA, Kuypers J, et al. (2002). Acquisition and natural history of human papillomavirus type 16 variant infection among a cohort of female university students. Cancer Epidemiol. Biomarkers Prev. 11: 343-351.

Xi LF, Kiviat NB, Hildesheim A, Galloway DA, et al. (2006). Human papillomavirus type 16 and 18 variants: race-related distribution and persistence. J. Natl. Cancer Inst. 98: 1045-1052.

Yamada T, Manos MM, Peto J, Greer CE, et al. (1997). Human papillomavirus type 16 sequence variation in cervical cancers: a worldwide perspective. J. Virol. 71: 2463-2472. 